\title{
/COMMENTARY
}

\section{Environmentally Correct Biotechnology}

\author{
BERNARD DIXON
}

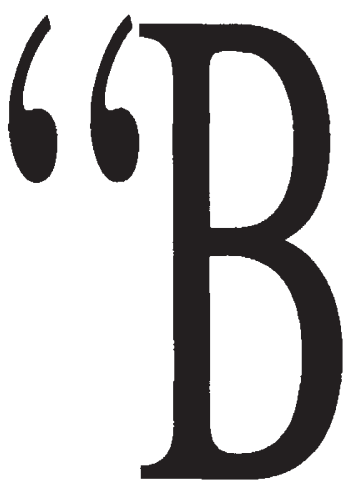

iotechnology entails the harnessing of organisms or their components to undertake specific processes that are, in principle, advantageous to society. There are many applications of biotechnology in fields as diverse as medicine, agriculture, industry, and resource recovery and recycling. . . Genetic engineering, a subdiscipline of biotechnology that allows gene components to be manipulated and transferred across species, is opening up a new array of opportunities. .. . Biotechnology represents one of the most exciting advances in the biological sciences this century."

Assertions acquire meaning, conviction, and significance not just from their wording but from their source and context, too. The remarks above-unremarkable to readers of Bio/Technology, banal evenare notable only because of the position of the person who uttered them.

These sentences are taken not from a bioindustry handout or schools primer, but from a speech reflecting the approach to biotechnology taken by the United Nations Environment Program (UNEP). Delivered in Madras earlier this year by UNEP's Assistant Executive Director Reuben Olembo on behalf of Executive Director Elizabeth Dowdswell at the Second AsiaPacific Conference of Agricultural Biotechnology, they have been surprisingly neglected by the media and by commentators. For this was a remarkable speech. Contrasting starkly with the predominantly hostile attitude of countless smaller environmental organizations throughout the world toward biotechnology, they represent a rousing endorsement of its value for poorer nations and for the cause of environmental protection generally.

I've long been perplexed by the antipathy toward science and technology shown by many of those very individuals and groups who claim to be concerned with the integrity and future of the biosphere. Do they not realize that technical analysis and know-how are essential at every stage in their quest? How could we possibly even discern that the ozone layer may be thinning, without some extremely sensitive analytical methodology? How to deal with effluents, or clean up the atmosphere or oceans, without technology? What is ecology but a science?

Some environmentalists do, of course, take a more enlightened position. They recognize that while un- bridled technology can run amok, sensitively applied science is a force for human welfare and planetary well-being. (A nice example of environmental biotech at work can be seen in this month's research section in the paper by Woodward et al. "Enzymatic Separation of High-Quality Uninked Pulp Fibers from Recycled Newspaper.')

But the prevailing tone, especially among environmental campaigners, is one of carping suspicion or outright rejection. Even within the European Union, the regulation of GMOs has been a battleground for tussles between that part of the European Commission which is concerned with research and development and that dedicated to environmental interests.

Reuben Olembo's Madras speech was refreshingly positive. Much of it was written in light of the Rio Conference on Environment and Development and the Convention on Biological Diversity. Again, the majority of environmental lobbyists have reacted to both that event and the convention by shaking their heads in angry disappointment over the "missed opportunities" and the "failure to tackle the real issues."

Olembo disagrees. "Biotechnology is acknowledged to have much to offer to biodiversity conservation and its sustainable use," he says, instancing measures to enhance and restore the resilience of ecosystems; the rehabilitation of degraded habitats, and the development of in situ and ex situ conservation facilities. Even more surprisingly, he welcomes "the genetic engineering of living organisms or parts thereof into novel forms, varieties, or breeds with desired environmental, physiological, behavioral, and other traits."

Biotechnology certainly has the power to be a major player in sustainable development, but any truly objective analysis is bound to indicate that this potential lies overwhelmingly on the positive side of the balance sheet. While there are risks in the deployment of any new technology, these have to be set against a vast dossier of beneficent developments, including unprecedented advances in plant breeding, increased genetic diversity, greater resource recovery and recycling, health improvements through novel vaccines and drugs, and the enhancement of the natural environment.

Speaking in Madras, Reuben Olembo did not minimize the conjectural dangers associated with, for example, the release of GMOs. Yet, by far his strongest message — on UNEP's behalf — was that biotechnology, harnessed through prudent, proactive national and international legislation, offers enormous promise. I hope the environmentalists are listening. III 